\title{
Bovine Trypanosomosis and Tsetse Fly Vectors in Abobo and Gambela Districts, Southwestern Ethiopia
}

\section{Mohamed Kedir ${ }^{1}$, Kumela Lelisa ${ }^{2 *}$ and Delesa Damena ${ }^{3}$}

${ }^{1}$ National Tsetse and Trypanosomosis Investigation and Control Center, Bedele, Ethiopia

${ }^{2}$ National Institute for Control and Eradication of Tsetse Fly and Trypanosomosis, Ethiopia

${ }^{3}$ National Animal Health Diagnostic and Investigation Center, Sebeta, Ethiopia

\begin{abstract}
The study was conducted from October 2015 to November 2015 in Gambela and Abobo districts of Gambela Peoples Regional State, southwestern Ethiopia. It was designed to avail information on prevalence of bovine trypanosomosis and apparent densities of vectors of the trypanosomosis. A parasitological study using buffy coat technique was employed for the determination of prevalence of trypanosomosis while baited mono pyramidal traps were used for the vector survey. A total of 862 cattle randomly selected from the study population were examined for the parasitological study. The result of parasitological study revealed that the overall prevalence of trypanosomosis was found to be $16.59 \%, 95 \% \mathrm{Cl}=14.10-19.08$ indicating trypanosomosis is a serious problem in the area. Three Trypanosoma species were identified during the study period: Trypanosoma brucei, $T$. vivax and T. congolense. Highest trypanosome prevalence (18.67\%) was seen in animals with poor condition than that of those with medium $(16.76 \%)$ and good $(14.20 \%)$ body condition for the concerned blood parasite but no significant difference was observed $(P>0.05)$. Higher infection rate was occurred in male $(18.35 \%)$ than female $(14.79 \%)$ cattle without significant difference $(P>0.05)$. Prevalence was significantly higher in adult animals $(17.95 \%)$ than younger ones $(7.27 \%)(P>0.05)$. The study suggested that mean PCV values of parasitaemic $(21.13 \%)$ cattle was significantly lower than aparasitaemic $(22.26 \%)$ animals $(P<0.05)$. During entomological survey, four species of tsetse fly: $G$. tachnoides, G. morsitsns submorsitans, G. pallidipes and G. fuscipes fuscipes and three genera of other biting flies: Tabanus, Haematopota and Stomoxys spp. were caught. The overall apparent density of tsetse flies was 0.75 fly/trap/day. Trypanosomosis and tsetse fly pose great threat to cattle residing in study areas. Thus, appropriate intervention measures need to be taken.
\end{abstract}

Keywords: Abobo; Density; Gambela; Prevalence; Trypanosomosis; Tsetse fly

\section{Introduction}

Trypanosomosis is an endemic disease to east Africa including Ethiopia [1]. Bovine trypanosomosis is one of the diseases that are caused by flagellated protozoan parasites belong to the genus Trypanosoma [2]. Trypanosomosis limits the extension of natural herds in Africa where the presence of tsetse fly density access to woody land and savannah areas with good grazing potential. It is a serious constraint to agricultural production in extensive areas of the tsetse infested regions [3] which accounts over 10 million square kilometers of the tropical Africa. The reduced capacity for work animals is also a very important factor where $80 \%$ of the traction power in African agriculture is provided by animals. In general, there is a great threat of trypanosomosis which impedes the economic development of Africa.

Out of six species of trypanosomes are recorded in Ethiopia, three are the most important trypanosomes in terms of economic loss in domestic livestock and are tsetse transmitted species. These include Trypanosoma congolense, T. vivax and T. brucei. Tsetse flies are principal vector of African animal trypanosomosis and Sleeping Sickness. Tsetse flies in Ethiopia are confined to southwestern and northwestern regions between longitude $33^{\circ}$ and $38^{\circ} \mathrm{E}$ and latitude $5^{\circ}$ and $12^{\circ} \mathrm{N}$ covers an area of $220,000 \mathrm{~km}^{2}$. Tsetse infested areas lie in the river basins of Blue Nile, Baro-Akobo, Didessa, Ghibe, and Omo. Five species of Glossina (G. m. submorsitans, G. pallidipes, G. tachinoides, G. f. fuscipes and G. longipennis) have been investigated in Ethiopia [4] out of which the first four are distributed widely in western and south western part of the country. Tsetse transmitted animal trypanosomosis still remains as one of the major causes of livestock mortality and production losses in western, southwestern and northwestern lowlands of Ethiopia [5], although trypanosomosis can also be transmitted by other blood sucking insects.

Currently, trypanosomosis is found to be one of the factors hampering livestock production and productivity in most parts of western and south western Ethiopia. An understanding of the prevalence of the disease and magnitude of the vector population is crucial for designing appropriate control strategies. Therefore, the aim of this research was to estimate the infection rate of trypanosomosis in cattle and relative abundance of Glossina species and other biting flies responsible for transmitting the disease in Gambela and Abobo districts, Southwestern Ethiopia.

\section{Materials and Methods}

\section{Study area}

The study was conducted from October to November 2015 in five peasant associations of Gambela district and five peasant associations of Abobo district located in Gambela regional sate. The districts are situated at 766 and 811 Kilometers South West of Addis Ababa respectively. The

*Corresponding author: Kumela Lelisa Dera, National Institute for Control and Eradication of Tsetse Fly and Trypanosomosis, PO Box 19917, Addis Ababa Ethiopia, Tel: +251-912-912-079; E-mail: lelisakumela@gmail.com

Received August 01, 2016; Accepted August 29, 2016; Published September 02,2016

Citation: Kedir M, Lelisa K, Damena D (2016) Bovine Trypanosomosis and Tsetse Fly Vectors in Abobo and Gambela Districts, Southwestern Ethiopia. J Vet Sci Technol 7: 380. doi: 10.4172/2157-7579.1000380

Copyright: ( 2016 Kedir M, et al. This is an open-access article distributed under the terms of the Creative Commons Attribution License, which permits unrestricted use, distribution, and reproduction in any medium, provided the original author and source are credited. 
mean annual rain fall in both Gambela and Abobo districts ranges from $1000-2000 \mathrm{~mm}$. The annual temperature ranges from $27-40^{\circ} \mathrm{C}$. Both districts have altitudes ranging from 400-520 meters above sea level. The areas are well known by their diversified wildlife such as buffaloes, elephants, lions, leopards, cheetahs, giraffes, hartebeest, baboons, Bush pigs, warthog, bush buck, kudu, hippopotamus, crocodiles, and antelopes etc. which might be claimed to serve as sources of food for tsetse fly and as reservoir for trypanosomes (Figure 1).

\section{Study population, sampling design and sample size determination}

The cattle in the study areas are local breeds that are kept under traditional extensive husbandry systems with communal herding. The animal population of the Gambela district is estimated to be 1752 cattle, 325 sheep, 1194 goats, and 13 equines and Abobo has an estimated 4049 cattle, 44 sheep, 2141 goats, 116 equines population.

A cross-sectional study was conducted in ten purposively selected villages of Gambela and Abobo districts, Gambela Peoples Regional State, southwest Ethiopia. Then simple random sampling technique was followed to select individual study animals. The number of animals required for the study was determined using the formula given by Thrusfield [6] for simple random sampling. The size of sample was determined using $95 \%$ level of confidence, $50 \%$ expected prevalence and 0.05 desired absolute precision. Therefore, a total of 384 cattle were needed for the study even though, samples collected from 862 cattle was examined. The sex, body condition and origin of cattle including districts and peasant associations were explanatory variables used to associate with the prevalence. Body condition for each cattle was estimated based on Nicholson and Butterworth [7]. Whilst, age of study animals was determined by dentition according to De Lahunte and Habel [8] and categorized into two age groups as adult ( $>3$ years) and young ( $\leq 3$ years).

\section{Study methodology}

Survey of trypanosomes: Blood samples were collected in to heparinized micro hematocrit tubes (Deltalab S.L, Bercelona, Spain) after piercing the ear vein using lancet. Then one end of the capillary tube was sealed with sealant (Hawksley Ltd, Lancing, UK) and centrifuged at 12,000 revolutions per minute (rpm) for five minutes to separate the blood cells and to concentrate trypanosomes using centrifugal force as buffy coat. Then Packed Cell Volume (PCV) was determined using hematocrit reader and recorded. The capillary tubes were then broken just below buffy coat and expressed on microscopic slide, mixed and covered with a $22 \times 22 \mathrm{~mm}$ cover slip. Then it was examined under $\mathrm{x} 40$ objective of microscope using dark ground Buffy coat technique to detect the presence of motile trypanosomes and for positive samples Geimsa stain of thin blood smears were made, fixed with methanol for 5 minutes, and examined under oil immersion using $\mathrm{x} 100$ objective to identify the species of trypanosomes [9].

Entomological study: A total of 145 baited mono-pyramidal traps were deployed along suitable tsetse habitats to assess the apparent densities, distributions and species of tsetse flies and other haematophagus flies involving in transmission of trypanosomes. All traps were baited with acetone, Octenol (1-3-Octane) and cow urine filled in separated bottles and labeled and deployed at an interval of 200-250 meters. After 48 hours of trap deployment time the cages
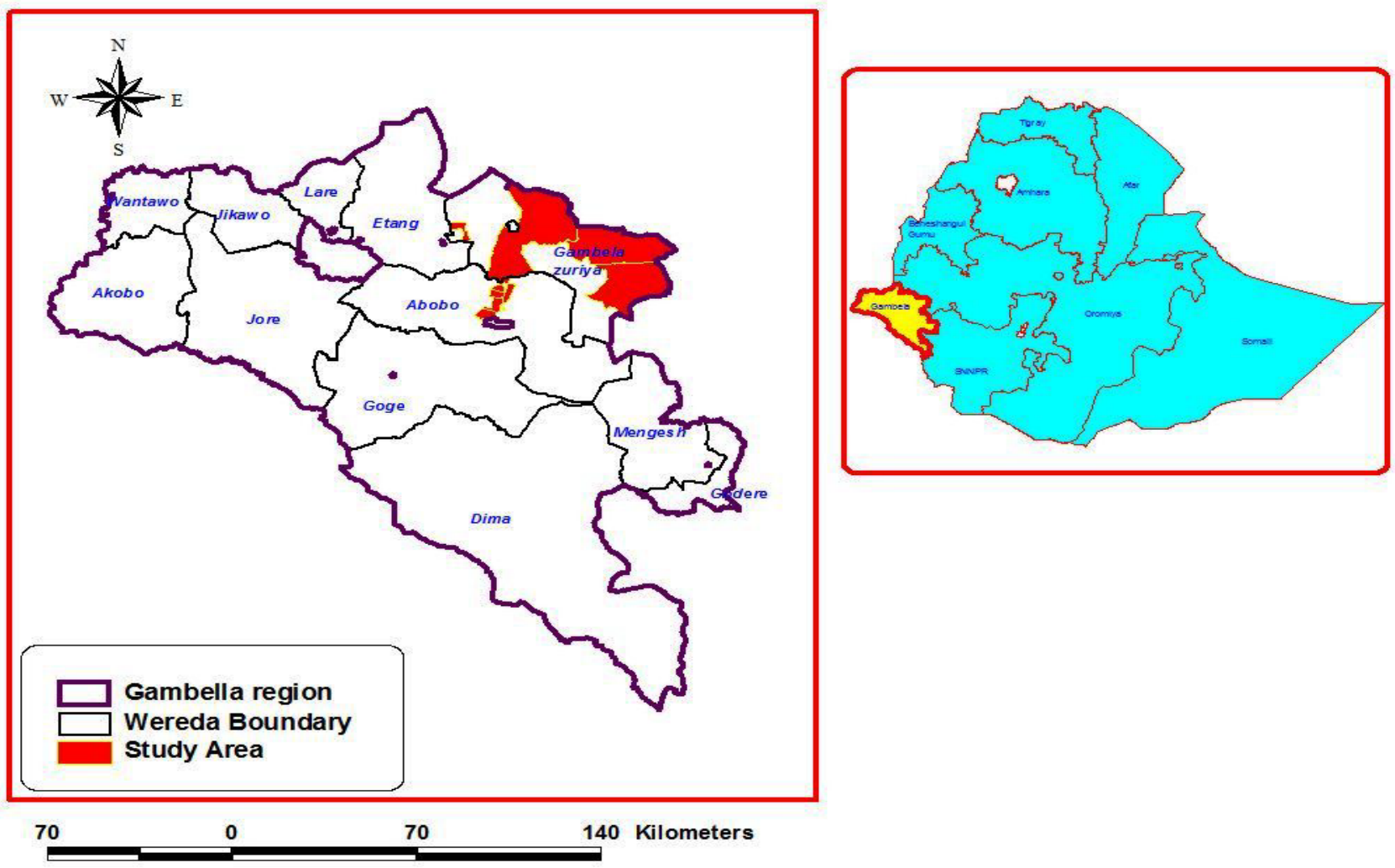

Figure 1: Map showing locations of study areas in Gambela region, South West Ethiopia 
were collected and captured flies were identified and sexed according to morphological characteristics and counted. The tsetse flies were identified to species level and the other biting flies to the genus level [10].

\section{Data management and analysis}

The data collected were entered in to Microsoft Excel Data base system. The entered data were analyzed using STATA version 10 statistical software program. The prevalence of trypanosomosis was calculated by dividing the proportion of cattle infected with one and/or more trypanosome species by the total number of cattle examined multiplied by 100 . The association between the prevalence of trypanosome infection and associated risk factors were assessed by logistic regression, whereas the student's t-test was used to assess the difference in mean PCV between trypanosome positive and negative animals. A statistically significant association between variables was said to exist if the calculated $\mathrm{P}<0.05$ at $95 \%$ confidence level. Finally, the density of fly population is calculated by dividing the number of flies caught by the number traps deployed and number of days of deployment, and expressed as fly/trap/day (FTD).

\section{Results}

\section{Parasitological findings}

From the total examined cattle $(\mathrm{n}=862), 143(16.59 \%, 95 \% \mathrm{CI}=14.10$ 19.08) were found to be infected with trypanosomes. Out of the total 580 cattle examined, $105(18.10 \%)$ cattle were positive for trypanosomosis in Abobo district, while 38 (13.48\%) were infected with trypanosomes out of the 282 examined cattle in Gambela district $\left(\chi^{2}=2.94 ; \mathrm{P}=0.09\right)$. The prevalence was varying from $12.50 \%$ to $29.82 \%$ in Abobo district. In Gambela district the infection rate of bovine trypanosomes was ranging from $9.64 \%$ to $58.82 \%$ (Tables 1 and 2).

Infection rate was $18.35 \%$ and $14.79 \%$ in male and female respectively. Higher prevalence of trypanosomosis was recorded in adult animals (17.95\%) than younger ones (7.27\%). Similarly, anemic cattle (PCV $\leq 24 \%)$ had higher trypanosomes prevalence than those with PCV values within the normal range (25_48\%) (Table 3).

The proportion of trypanosome infection with species level indicated $94(65.73 \%)$ were found to be infected by T. vivax, $36(25.17 \%)$ were found to be infected by $T$. congolense; $3(2.10 \%)$ were infected by T. brucei and $10(6.99 \%)$ were mixed infections $\left(\chi^{2}=862 ; \mathrm{P}=0.00\right)$.

The prevalence in male and female animals was $18.35 \%$ and $14.79 \%$, respectively. Of the 110 young and 752 adult animals examined, $7.27 \%$ and $17.95 \%$ tested positive for trypanosome infection, for young and adults, respectively. Significantly higher prevalence was recorded in adult animals as compared to the young ones. Higher prevalence of trypanosomosis was recorded in animals with a poor body condition $(18.67 \%)$ than in those in medium (16.76\%) and good body condition (14.20\%).

\section{Hematological findings}

The overall mean PCV values of examined cattle was $22.07 \pm 4.83$ $(/ \mathrm{t} /=00, \mathrm{DF}=8, \mathrm{SE}=0.16, \mathrm{p}=0.00,95 \% \mathrm{CI}=21.75-22.39)$. Cattle with good body condition had highest $(23.78 \%, \mathrm{SE}=0.38,95 \% \mathrm{CI}=23.04-24.51)$ mean PCV value followed by medium $(20.02 \mathrm{SE}=0.20,95 \% \mathrm{CI}=21.63-$ $22.41)$ and poor $(22.43, \mathrm{SE}=0.39,95 \% \mathrm{CI}=19.56-21.10)$. The mean $\mathrm{PCV}$ of parasitaemic and aparasitaemic animals was $21.13 \%, 95 \% \mathrm{CI}=20.39$ 21.86 and $22.26 \%, 95 \% \mathrm{CI}=21.90-22.62$ respectively.

\section{Entomological findings}

The tsetse flies found during the study period were Glossina $\mathrm{m}$. submorsitans, G. pallidipes, G. fuscipes fuscipes and G. tachnoides and other biting flies particularly genus Stomoxys, Haematopota and Tabanus. A total 3154 blood sucking flies were caught during the study period of which 218 (6.91\%) were tsetse fly, 14(0.44\%) were Stomoxys, $11(0.35 \%)$ were Haematopota and 2911 (92.30\%) were Tabanids. The overall fly species caught was $10.88 \mathrm{fly} /$ trap/day. The apparent densities of Glossina, Tabanus, Haematopota and Stomoxys were $0.75,10.04$ 0.04 and 0.05 flies/trap/day respectively. The apparent densities of Glossina species was 0.24 and $1.09 \mathrm{fly} / \mathrm{trap} /$ day in Gambela and Abobo districts, respectively. The sex category indicated male and female tsetse fly account for $36.70 \%$ and $63.30 \%$ of total caught Glossina species, respectively.

\section{Discussion}

Bovine trypanosomosis affects cattle which have a major role in the economy of Ethiopia. Prevalence of trypanosomosis in Gambela and Abobo areas, located in Baro Akobo water basin during the study period was found to be $16.59 \%$. This result is fairly similar with earlier report from different parts of Ethiopia and from abroad: $14.68 \%$ in north western Ethiopia [11], 16.44\% in northern Cameroon [12] and $17.33 \%$ in southern Ethiopia [13]. Infection rate is significantly higher in Bonga village $(58.82 \%)(\mathrm{P}<0.05)$. This might be related with high density of blood sucking insects in the village. The prevalence of trypanosomosis in Gambela and Abobo districts was $13.48 \%$ and $18.10 \%$, respectively. However, there was no statistically significant difference $(p>0.05)$ between these two districts. This may be related with similarity of the two districts in vegetation and other epidemiological factors such as cattle breed and management system.

The present result revealed that the trypanosome species encountered in the area were T. vivax, T. congolense and T. brucei.

\begin{tabular}{|c|c|c|c|c|c|c|}
\hline \multirow{2}{*}{$\mathrm{BC}$ result } & \multicolumn{5}{|c|}{ Peasant Associations } & \multirow{2}{*}{ Total } \\
\hline & Village 17 & Village 14 & Village 13 & Village 11 & Village 7 & \\
\hline Negative & $92(86.79 \%)$ & $40(70.18 \%)$ & $60(74.07 \%)$ & $124(78.98 \%)$ & $84(87.50 \%)$ & $475(81.90 \%)$ \\
\hline Positive & $14(13.21 \%)$ & $17(29.82 \%)$ & $21(25.93 \%)$ & $33(21.02 \%)$ & $12(12.50 \%)$ & $105(18.10 \%)$ \\
\hline Total $(\mathrm{N})$ & 106 & 57 & 81 & 157 & 96 & 580 \\
\hline
\end{tabular}

Table 1: Prevalence of bovine trypanosomosis in different peasant associations of Abobo district.

\begin{tabular}{|c|c|c|c|c|c|c|}
\hline \multirow{2}{*}{$B C$ result } & \multicolumn{5}{|c|}{ Peasant Associations } & \multirow{2}{*}{ Total } \\
\hline & Village 8 & Bonga & Elchiwe & Abol & Opanga & \\
\hline Negative & $75(90.36 \%)$ & $7(41.18 \%)$ & $17(70.83 \%)$ & $136(97.14 \%)$ & $84(83.17 \%)$ & $244(86.52 \%)$ \\
\hline Positive & $8(9.64 \%)$ & $10(58.82 \%)$ & $7(29.17 \%)$ & $4(2.86 \%)$ & $17(16.83 \%)$ & $38(13.48 \%)$ \\
\hline Total $(\mathrm{N})$ & 83 & 17 & 24 & 140 & 101 & 282 \\
\hline
\end{tabular}

Table 2: Prevalence of bovine trypanosomosis in different peasant associations of Gambela district. 


\begin{tabular}{|c|c|c|c|c|c|}
\hline Variables & No. of negative & No. of positive & Total & $x^{2}$ & P-value \\
\hline \multicolumn{4}{|c|}{ Districts } & & \\
\hline Gambela & $244(86.52 \%)$ & $38(13.48 \%)$ & $282(32.71 \%)$ & \multirow{3}{*}{2.94} & \multirow{3}{*}{0.09} \\
\hline \multirow[t]{2}{*}{ Abobo } & $475(81.90 \%)$ & $105(18.10 \%)$ & $580(67.29 \%)$ & & \\
\hline & $719(83.41 \%)$ & $143(16.59 \%)$ & $862(100 \%)$ & & \\
\hline \multicolumn{4}{|c|}{ Sex } & \multirow{4}{*}{1.97} & \multirow{4}{*}{0.16} \\
\hline Male & $356(81.65 \%)$ & $80(18.35 \%)$ & $436(50.58 \%)$ & & \\
\hline \multirow[t]{2}{*}{ Female } & $363(85.21 \%)$ & $63(14.79 \%)$ & $426(49.42 \%)$ & & \\
\hline & $719(83.41 \%)$ & $143(16.59 \%)$ & $862(100 \%)$ & & \\
\hline & Bod & on & & \multirow{5}{*}{1.18} & \multirow{5}{*}{0.56} \\
\hline Good & $145(85.80 \%)$ & $24(14.20 \%)$ & $169(19.61 \%)$ & & \\
\hline Medium & $452(83.24 \%)$ & $91(16.76 \%)$ & $543(62.99 \%)$ & & \\
\hline \multirow[t]{2}{*}{ Poor } & $122(81.33 \%)$ & $28(18.67 \%)$ & $150(17.40 \%)$ & & \\
\hline & $719(83.41 \%)$ & $143(16.59 \%)$ & $862(100 \%)$ & & \\
\hline \multicolumn{4}{|l|}{ Age } & \multirow{4}{*}{7.91} & \multirow{4}{*}{$0.01^{* *}$} \\
\hline Young & $102(97.73 \%)$ & $8(7.27 \%)$ & $110(12.76 \%)$ & & \\
\hline \multirow[t]{2}{*}{ Adult } & $617(87.05 \%)$ & $135(17.95 \%)$ & $752(87.24 \%)$ & & \\
\hline & $719(83.41 \%)$ & $143(16.59 \%)$ & $862(100 \%)$ & & \\
\hline PCV & & & & \multirow{4}{*}{4.21} & \multirow{4}{*}{$0.04^{* *}$} \\
\hline$\leq 24 \%$ & $502(81.76 \%)$ & $112(18.24 \%)$ & $614(71.23 \%)$ & & \\
\hline \multirow[t]{2}{*}{$>24 \%$} & $217(87.50 \%)$ & $31(12.50 \%)$ & $248(28.77 \%)$ & & \\
\hline & $719(83.41 \%)$ & $143(16.59 \%)$ & $862(100 \%)$ & & \\
\hline
\end{tabular}

Table 3: Prevalence of bovine trypanosomosis and associated risk factors in Gambela and Abobo districts.

These three species of trypanosomes were also reported from western and south western part of Ethiopia by Lemecha et al. [14] in Ghibe valley, Tilahun et al. [15] in Dale Sadi district; Habte et al. [16] in Darimu district and Lelisa et al. [17] in southwestern Ethiopia. The study showed that $T$. vivax was the predominant (65.73\%) species in the area. Similar reports were made previously by Mhiret and Mamo [18] in East Gojjam, North West Ethiopia and Tadesse et al. [19] in Northwestern Ethiopia. This may be associated to the presence high density of biting flies that are mechanical vector of trypanosomes ( $T$. vivax) which can be transmitted by tsetse flies and/or other blood sucking insects like Tabanus, Haematopota and Stomoxys spp. [20].

The prevalence of trypanosomosis in male and female animals was $18.35 \%$ and $14.79 \%$, respectively. The difference in prevalence between the sex groups was not statistically significant $(p>0.05)$. Of the 110 young and 752 adult animals examined, $7.27 \%$ and $17.95 \%$ tested positive for trypanosome infection, respectively. Significantly higher prevalence was recorded in adult animals as compared to the young ones $(\mathrm{P}<0.05)$. This might be due to increased exposure of adult cattle to vectors of trypanosomes. Dagnachew [21], Tekle and Mekonen [22] and Mulatu et al. [23] also reported significantly higher infection rate in older cattle. Although the difference is not significant $(p>0.05)$, higher prevalence of trypanosomosis was higher in animals in a poor body condition (18.67\%) than in those in medium (16.76\%) and good body condition (14.20\%) indicating weight loss is one of the symptoms of trypanosomosis [24].

The study also indicated that the mean PCV values of investigated cattle of the study area was negatively correlated $(\mathrm{r}=-0.09)$ with trypanosomosis prevalence, that is, mean PCV was decreased with increasing prevalence of infection. The mean PCV value of parasitaemic animals was $21.13 \%, \mathrm{SE}=0.38,95 \% \mathrm{CI}=20.39-21.86$ and aparasitaemic animals was $22.26 \%, \mathrm{SE}=0.18,95 \% \mathrm{CI}=21.90-22.62$. Measuring the mean PCV value is one of the indicator of a herd infected with trypanosomosis and hence the anemic status of sampled animals showed reduced PCV values. Such result was also reported by Lelisa et al. [25]; Tasew and Duguma [26]; Zecharias and Zeryehun [27]; Kassaye and Tsegaye [28]. Thus, the development of anemia is the most reliable indication of the progress of the trypanosome infection. There are also parasitoloically negative animals within the PCV values of less than the threshold value $(\leq 24 \%)$. This may be due to in adequacy of detection method (Buffy coat technique) or delayed recovery of anemic situation after current treatment with trypanocidal drugs. Other blood parasites infection like babesiosis and theileriosis [29] and malnutrition can also lead to the development of anemia. Whilst, the occurrences of parasitologically positive cattle with PCV greater than $25 \%$ might be thought of recent infections of animals with trypanosomes.

In this study, the entomological findings revealed that four species of Glossina (Glossina m. submorsitans, G. pallidipes, G. fuscipes fuscipes and G. tachnoides) out of five reported in Ethiopia and other biting flies of genera Stomoxys, Haemtopota and Tabanids occur Gambela and Abobo districts, Gambela Peoples Regional State, South west Ethiopia. These four tsetse specie also reported by Duguma et al. [30] in western and Southwestern Ethiopia. The apparent densities of Glossina species was 0.24 and 1.09 fly/trap/day in Gambela and Abobo districts respectively. This result is in agreement with different reports in western, south, south western and north western part of the country: 1.45 and $0.58 \mathrm{fly} /$ trap/day in two districts of East Wollega zone, western Ethiopia [31], and 1.14 fly/trap/day in Southern Rift Valley of Ethiopia [32]. The sex category indicated male and female tsetse fly account for $36.70 \%$ and $63.30 \%$ of total caught Glossina species, respectively. The higher number of female than males might be related with the longer lifespan of female than male tsetse flies.

In conclusion, the present study indicated that tsetse transmitted trypanosomosis is a potential threat for cattle residing in the area. Thus, trypanosomosis and tsetse control methods should be expanded to reach all infested areas in sustainable manner besides participatory extension packages to create public awareness. Further epidemiological investigation is also a necessity to synchronize control efforts at national level and detail survey of human African trypanosomosis also should be undertaken.

\section{References}

1. Shaw APM, Cecchic G, Wintd GRW, Mattiolie RC, Robinson TP (2014) Mapping the economic benefits to livestock keepers from intervening against bovine trypanosomosis in Eastern Africa. Prev Vet Med 113: 197-210. 
Citation: Kedir M, Lelisa K, Damena D (2016) Bovine Trypanosomosis and Tsetse Fly Vectors in Abobo and Gambela Districts, Southwestern Ethiopia. J Vet Sci Technol 7: 380. doi: 10.4172/2157-7579.1000380

2. Uilenberg $G$ (1998) A field guide for the diagnosis, treatment and prevention of African animal trypanosomosis, Food and Agriculture Organization of the United Nations, Rome.

3. Slingenbergh J (1992) Tsetse control and agricultural development in Ethiopia. World Anim Rev 70-71: 30-36.

4. Abebe G (2005) Trypanosomosis in Ethiopia. Ethiop J Biol Sci 4: 75-121.

5. NTTICC (2004) Annual Report on Tsetse and Trypanosomosis Survey, National Tsetse and Trypanosomosis Investigation and Control Center Bedele, Ethiopia.

6. Thrusfield M (2005) Veterinary epidemiology. 3rd edn, Black well science, Oxford, p: 233

7. Nicholson MJ, Butterworth MH (1986) A guide to body condition scoring of zebu cattle. International Livestock Research Center for Africa, Addis Ababa Ethiopia.

8. DeLahunta A, Habel RE (1986) Teeth. In: Applied Veterinary Anatomy DeLahunta A and Habel RE (eds.). W.B. Saunders Company, Philadelphia USA.

9. Murray M, Trail JCM, Turner DA, Wissocq Y (1983) Livestock productivity and trypanotolerance: Network training manual. International Livestock Centre for Africa (ILCA), Addis Ababa.

10. Wall R, Shearer D (1997) Veterinary Entomology. Arthropod Ectoparasites of Veterinary Importance. London, UK, Champman and hall, pp: 141-193.

11. Dagnachew S, Sangwan AK, Abebe G (2005) Epidemiology of bovine trypanosomosis in the Abay (Blue Nile) Basin Areas of Northwest Ethiopia. Rev D"Elev Et De Med Vet Des Pays Trop 58: 151-157.

12. Achukwi MD, Musongong GA (2009) Trypanosomosis in the Doayo/Namch (Bos taurus) and zebu White Fulani (Bos indicus) cattle in Faro Division, North Cameroon. J App Biosci 15: 807-814.

13. Zeleke G (2011) Preliminary survey on tsetse flies and trypanosomosis a grazing fields and villages in and around the Nech Sar National Park, Southern Ethiopia. Ethiop Vet J 15: 59-67.

14. Lemecha H, Mulatu W, Hussein I, Rege E, Tekle T, et al. (2006) Response of four indigenous bovine breeds to natural tsetse and trypanosomosis challenge in the Ghibe valley of Ethiopia. Vet Parasitol 141: 165-176.

15. Tilahun Z, Jiregna D, Solomon K, Haimanot D, Girma K, et al. (2014) Prevalence of Bovine Trypanosomosis, its Vector Density and Distribution in Dale Sadi District, Kellem Wollega Zone, Ethiopia. Acta Parasitol Glob 5: 107-114.

16. Habte F, Kebede A, Desta T (2015) Study on Spatial Distribution of Tsetse Fly and Prevalence of Bovine Trypanosomosis and other Risk Factors: Case Study in Darimu District, llu Aba Bora Zone, Western Ethiopia. J Pharmacy and Alt Med, p: 7.

17. Lelisa K, Damena D, Tasew T, Kedir M, Megersa M (2016) Prevalence of Bovine Trypanosomosis and Vector Distributions in Chewaka Settlement Area of llubabor Zone, Southwestern Ethiopia. Adv Biol Res 10: 71-76.
18. Mhiret A Mamo G (2007) Bovine trypanosomosis in three districts of East Gojjam zone bordering Blue Nile River in Ethiopia. J Infect Dev Ctries 1 : 321-325.

19. Tadesse E, Gashaw G, Assaye M (2015) Prevalence of Bovine Trypanosomosis in Bure and Womberma Districts of West Gojjam Zone, North West Ethiopia. Acta Parasitol Glob 6: 164-173.

20. Gooding RH, Krafsur ES (2005) Tsetse Genetics: Contributions to Biology, Systematics, and Control of Tsetse Flies. Annu Rev Entomol 50: 101-123.

21. Dagnachew S (2004) Epidemiology of bovine trypanosomosis in the Abay Basin Areas of Northwestern Ethiopia. Addis Ababa University, Faculty of Veterinary Medicine, MSc Thesis, Debre Zeit, Ethiopia

22. Tekle Y (2013) Prevalence of Bovine Trypanosomosis in Tsetse Controlled and Uncontrolled Areas of Eastern Wollega, Ethiopia. J Sci and Innov Res 2: 61-75.

23. Mulatu E, Lelisa K, Damena D (2016) Prevalence of Bovine Trypanosomosis and Apparent Density of Tsetse Flies in Eastern Part of Dangur District, North Western Ethiopia. J Vet Sci Technol 7: 347.

24. Radostitis OM, Gay C, Blood DC (2007) Veterinary Medicine: A text book of diseases of cattle, horse, sheep, pigs and goats. Balliere Tindal London, pp: 1531-1540.

25. Lelisa K, Shimelis, Bekele J, Shiferaw D (2014) Bovine trypanosomosis and its fly vectors in three selected settlement areas of Hawa-Gelan district, western Ethiopia. Onderstepoort J Vet Res 81: 715.

26. Tasew S, Duguma R (2012) Cattle anaemia and trypanosomiasis in western Oromia State, Ethiopia. Revue Méd. Vét 163: 581-588.

27. Zecharias A, Zeryehun T (2012) Prevalence of Bovine Trypanosomosis in Selected District of Arba Minch, SNNPR, Southern Ethiopia. Glob Vet 8 : 168-173.

28. Kassaye BK, Tsegaye D (2016) Prevalence of Bovine Trypanosomosis, Tsetse Density and Farmers Perceptions on the Impact of Control Program in Kellem Wollega Zone, Western Oromia, Ethiopia. J Veterinar Sci Technol 7:295.

29. Sahinduran S (2012) Protozoan Diseases in Farm Ruminants. In: A Bird'sEye View of Veterinary Medicine. Carlos C Perez-Marin (Ed.). INTECH Open Access Publisher.

30. Duguma R, Tasew S, Olani A, Damena D, Alemu D, et al. (2015) Spatial distribution of Glossina species and Trypanosoma species in south-western Ethiopia. Parasites \& Vectors 8: 430.

31. Tafese W, Melaku, A, Fentahun T (2012) Prevalence of bovine trypanosomosis and its vectors in two districts of East Wollega Zone, Ethiopia. Onderstepoort $J$ Vet Res 79: 1-4.

32. Muturi KS, Msangi S, Munstermann S, Clausen P, Getachew A, et al. (2000) Trypanosomosis Risk Assessment in Selected Sites of the Southern Rift Valley of Ethiopia. I. Distribution, Density and Infection Rates of Tsetse Flies. II. Epidemiology of Bovine Trypanosomosis. In: International Scientific Counci for Trypanosomiasis Research and Control (ISCTRC). Proceedings of the $25^{\text {th }}$ meeting held in Mombassa, Kenya. OAU/STRC No. 120. 